\title{
Música e Neurociências
}

Mauro Muszkat*

Cleo M. F. Correia**

Sandra M. Campos***

\section{RESUMO}

O artigo analisa a relação da música com as neurociências, particularmente a organização cerebral das funções musicais. Os estudos de neuroimagem funcional revelam que a lateralização e a topografia da ativação cerebral durante o estímulo musical relacionam-se a múltiplos fatores, como familiaridade ao estímulo, estratégia cognitiva utilizada para o reconhecimento melódico, rítmico e tímbrico e mesmo treinamento musical prévio. A relação entre a música e as mudanças na atividade elétrica cerebral é sugerida a partir dos casos da chamada epilepsia musicogênica, das descrições das manifestações "musicais" de crises parciais psíquicas ou dos relatos anedóticos de mudanças dos padrões eletrencefalográficos interictais durante a audição de músicas de Mozart.

\section{UNITERMOS}

Música, função cerebral, assimetria funcional cerebral.

\section{NTRODUÇÃO}

O tema que iremos discorrer é sobre as várias faces entre música e neurociência, principalmente no que tange à importância dos estudos em relação à organização cerebral das chamadas funções musicais. O interesse crescente nas pesquisas da relação música e cérebro, a meu ver, são reflexo de dois fatores. O primeiro relaciona-se à introdução recente de novas técnicas de neuroimagem, como a tomografia com emissão de pósitrons (TEP) e a ressonância magnética funcional (RMF), que permitem "visualizar" as mudanças funcionais e topográficas da atividade cerebral durante a realização de funções mentais complexas ${ }^{1,2,3,4}$. Assim, já é possível estudar as mudanças regionais do fluxo sangüíneo do metabolismo e da atividade elétrica cerebral durante tarefas de natureza cognitiva, como, por exemplo, enquanto um indivíduo processa estímulos sonoros, sejam estes meros sons puros senoidais, ruídos, padrões rítmicos ou mesmo "música", em sua acepção ampla. O interesse pela música relaciona-se ou reflete uma mudança de paradigma, que está ocorrendo tanto nas ciências humanas como nas ciências biológicas, e insere-se no terreno da interdisciplinaridade, no qual as especializações dão lugar às fronteiras e à unificação de áreas, antes seccionadas do conhecimento como as ciências e as artes. Neste contexto, não é de surpreender o crescente interesse na pesquisa das intricadas relações entre a "música" e a medicina, com ênfase à fisiologia, à neurologia e à psiquiatria.

\section{MÚSICA E CÉREBRO}

Inicialmente, é importante ressaltar aquilo que nós chamaremos de música em nossa exposição. Consideramos como música, independentemente de toda conotação estético-cultural que esta envolve, todo o processo relacionado à organização e à estruturação de unidades sonoras, seja em seus aspectos temporais (ritmo), seja na sucessão de alturas (melodia) ou na organização vertical harmônica e tímbrica dos sons. Entendemos por funções musicais o conjunto de atividades motoras e cognitivas envolvidas no processamento da música ${ }^{5}$. A música não resulta apenas da disposição de vibrações sonoras, mas sim da
Médico Neuropediatra e Doutor em Neurologia, EPM - Unifesp.

* Musicoterapeuta e Mestra em Neurociências, EPM - Unifesp.

*** Musicoterapeuta. 
estruturação dessas vibrações em padrões temporais organizados de signos, cuja forma, sintaxe e métrica constitui-se em um verdadeiro "sistema" independente e complexo, no qual significante e significado irão remeter-se à estrutura da própria música, isto é, à forma e ao estilo musical. Assim, falar sobre as relações fisiológicas, comportamentais, psíquicas e afetivas entre a música e o cérebro humano é remetermo-nos ao diálogo entre esses dois sistemas cibernéticos complexos autônomos e interdependentes - a música e o cérebro. Assim, o processamento musical envolve a integração bidirecional entre os componentes da estrutura e da sintaxe musicais (ritmo, estrutura, intencionalidade) e os componentes funcionais do próprio cérebro ${ }^{6,7}$. O reconhecimento de alterações fisiológicas, acompanhando o processamento musical, pode auxiliar o desenvolvimento, em bases funcionais, de procedimentos para intervenção musical adequados. Assim, as alterações fisiológicas da estimulação sonora podem refletir-se nas mudanças dos padrões, no reflexo de orientação, na variabilidade das respostas fisiológicas envolvidas em processos de atenção e expectativa musicais ou na mudança de freqüência, topografia e amplitude dos ritmos elétricos cerebrais ${ }^{6,7,8,9}$.

É importante ressaltar que o interesse pela relação música-cérebro não reside somente no fato de a estimulação sonora envolver funções neuropsicológicas bastante complexas com ativação de áreas corticais multimodais, mas pelo fato de a música estar, historicamente, inserida no campo das artes, com toda a conotação cultural e simbólica que isso acarreta. $\mathrm{O}$ fazer musical encerra e integra as funções do sentir, do processar, do perceber em estruturas ou em uma estética de comunicação que é, por si só, forma e conteúdo, corpo e espírito, mensageiro e mensagem.

A música, nas suas várias manifestações enquanto estética, terapia ou ritual, evoca o humano e sua contradição. Seus elementos de lógica, proporção e simetria estão intimamente relacionados e imbricados aos elementos de tensão, de relaxamento, que são sentidos, ou conceitualmente interpretados somente em bases abstratas que requerem a definição do homem, suas formas de sentir e pensar o mundo, e, portanto, seu sistema cultural e social de decodificação. Assim, não é de se estranhar que a evolução da estética musical do ocidente esteja intimamente relacionada com a evolução do pensamento científico de maneira indissociável.

\section{HISTÓRIAS PARALELAS - MÚSICA E CÉREBRO}

A música, em seus aspectos estruturais e na sua organização estritamente temporal, traduz e reflete a consciência que o homem tem do próprio tempo, seja este relacional (que lida com correlação linear entre os eventos, antecedente/conseqüente), ou psíquico (que traduz os processos perceptivos, cognitivos e afetivos em uma ordem que reflete ritmos circadianos internos, estados neurovegetativos e emocionais de expectativa, tensão ou repouso ${ }^{7,10}$ ).

No período medieval, a visão unidimensional do universo físico e a forma de pensamento intuitivo, de tendência espiritual, eram representadas por uma música monodimensional, de idioma modal, que expressava uma maneira de estar no mundo não dividida. Igualmente, o cérebro era interpretado como massa homogênia, um reservatório que distribuía seus humores vitais pelos ventrículos cerebrais. A partir do Renascimento, com a criação da perspectiva na pintura e da convergência tonal e harmônica na música, há a emergência de uma visão racionalista de um mundo dividido, que separa o eu (self) do espaço newtoniano que o circunda (mundo), no qual o tempo, métrico e facetado, representa e reflete as relações de causa-efeito. A música, basicamente temática, com um tempo métrico, sendo pulso, marcado na música barroca como o tiquetaque de um relógio, reflete o pensamento determinista de tendência racionalista e materialista. Essa música temática e métrica é a música que dominou a estética ocidental por mais de 500 anos. A visão dualista e racional desse período apresenta o cérebro como centro orgânico privilegiado da vida psíquica. Na visão dos frenologistas do século XIX, o cérebro era compartimentado em várias áreas, abrigando as diferentes funções psíquicas, como as emoções e os comportamentos humanos mais sutis, inclusive o amor à musica. A música contemporânea do início do século $\mathrm{XX}$ caracteriza-se pelo abandono a referências fixas como a tonalidade, organizando as estruturas sonoras a partir de configurações e inserindo a criação musical no probabilístico e na capacidade criadora do intérprete e do ouvinte. Neste enfoque, o tempo vivencial (não medido pelo relógio), o silêncio expressivo, a estrutura temporal assimétrica integram um fluxo multidirecional de sons em representações gráficas que evidenciam o tratamento dos signos sonoros enquanto eventos não lineares. Tais conceitos de espaço-tempo estão também intimamente ligados ao pensamento científico moderno, traçados nos fundamentos teóricos da física quântica e da teoria da relatividade. Neste sentido, aproximamo-nos da visão física ou material do mundo sob a óptica estética da nova música, uma vez que ambas traduzem a consciência auto-reflexiva, a maneira pela qual dimensionamos, relacionamos temporalmente e mesmo nomeamos nossos próprios processos psíquicos de “ver, 
decodificar, e reinterpretar" o mundo em que vivemos. Atualmente, o cérebro é visto como um sistema complexo de áreas específicas e não-específicas, colaborando à integração das funções cognitivas, afetivas e sensoriais. Esse sistema funcional atua de maneira concêntrica e complementar, atribuindo distintos papéis funcionais ao hemisfério cerebral direito e ao esquerdo (assimetria funcional hemisférica), e também com hierarquias distintas entre as diferentes áreas subcorticais e neocorticais. A maneira com que a ciência vê a relação entre o cérebro e as funções musicais surgiu conjuntamente aos estudos da chamada "Assimetria Funcional Hemisférica", e os trabalhos verdadeiramente pioneiros só foram realizados na segunda metade do nosso século, principalmente em pacientes portadores de epilepsia. Entre esses trabalhos, podemos ressaltar os de Critchley ${ }^{11}$ na descrição da epilepsia musicogênica; os de Penfield ${ }^{12}$, que durante estimulação elétrica cerebral, por procedimentos neurocirúrgicos, descreveram alucinações auditivas complexas quando da estimulação do giro temporal superior; os de Wada e Rasmussen ${ }^{13}$, que utilizando o teste de WADA, com a inativação temporária de um hemisfério cerebral pela injeção intracarotídea de amital sódico, verificaram, em alguns casos, a dificuldade para cantar, apesar da preservação da fala; o de Kimura ${ }^{14} \mathrm{com}$ as provas de estimulação auditiva (dicótica) de melodias demonstrando a superioridade do hemisfério direito para o processamento melódico, e os trabalhos mais recentes de Zatorre et al. ${ }^{4,15}$ e Chauvel et al. ${ }^{16}$ sobre as disfunções musicais em pacientes submetidos à lobectomia temporal.

\section{MÚSICA E NEUROIMAGEM}

A música, mais que qualquer outra arte, tem uma representação neuropsicológica extensa. Por não necessitar, como música absoluta, de codificação lingüística, tem acesso direto à afetividade, às áreas límbicas, que controlam nossos impulsos, emoções e motivação. Por envolver um armazenamento de signos estruturados, estimula nossa memória não-verbal (áreas associativas secundárias). Tem acesso direto ao sistema de percepções integradas, ligadas às áreas associativas de confluência cerebral, que unificam as várias sensações, incluindo a gustatória, a olfatória, a visual e a proprioceptiva em um conjunto de percepções que permitem integrar as várias impressões sensoriais em um mesmo instante, como a lembrança de um cheiro ou de imagens após ouvir determinado som ou determinada música. Também ativa as áreas cerebrais terciárias, localizadas nas regiões frontais, responsáveis pelas funções práxicas de seqüenciação, de melodia cinética da própria linguagem, e pela mímica que acompanha nossa reações corporais ao som ${ }^{17,18}$.

Recentemente, os recursos de neuroimagem funcional têm contribuído para novos e interessantes achados, enfatizando-se a importância da lateralização hemisférica na percepção musical. Tais trabalhos sugerem certo grau de independência funcional e anatômica para o processamento (ou para estratégia de processamento) dos vários parâmetros sonoros. Neste sentido, foi possível mapear, pelos trabalhos com TEP, as mudanças na ativação metabólica durante o processamento perceptivo e cognitivo dos constituintes da música. Assim, Mazziota et al. $^{3}$ observaram que, em tarefas de discriminação tímbrica, havia maior ativação de áreas frontais e temporais do hemisfério nãodominante. Lauter et al. ${ }^{19}$ confirmaram a organização tonotópica do córtex auditivo com ativação anterior e lateral para sons graves e médio e posterior para sons agudos. Zatorre et al. ${ }^{9}$ observaram que a audição melódica passiva envolvia, principalmente, regiões temporais do hemisfério direito, enquanto em provas mais ativas, que exigiam memória tonal, havia ativação de áreas frontais do hemisfério cerebral direito. Platel et al. ${ }^{13}$, em trabalho mais recente, estudaram a ativação de diferentes áreas cerebrais durante provas que envolviam alguns parâmetros psicoacústicos da música, a dizer: identificação de mudanças de altura, regularidade rítmica, familiaridade melódica, identificação de mudança tímbrica. Nas provas envolvendo familiaridade, havia maior ativação do giro temporal esquerdo e do giro frontal esquerdo. O reconhecimento tímbrico ativava o giro frontal superior e o giro póscentral direitos, enquanto as provas rítmicas envolviam áreas frontais inferiores e a ínsula do hemisfério esquerdo (dominante). Interessante também foi o fato de terem observado ativações de regiões occipitais, durante tarefa envolvendo o reconhecimento das alturas sonoras, sugerindo existir um recrutamento de áreas envolvidas nos processamentos das imagens como uma estratégia visual para a decodificação das alturas dos sons. Além disso, observaram, também, que durante tarefas rítmicas, ocorrem ativações na área de Broca $(\mathrm{AB}$ 44/6) estendendo-se à ínsula vizinha, sugerindo que essa região cerebral tem um importante papel no processamento de sons seqüenciais, o que sugere existir um elo neurobiológico entre o ritmo musical e a fala expressiva.

De um modo geral, as funções musicais parecem ser complexas, múltiplas e de localizações assimétricas, envolvendo o hemisfério direito para altura, timbre e 
discriminação melódica, e o esquerdo para ritmos, identificação semântica de melodias, senso de familiaridade, processamento temporal e seqüencial dos sons. No entanto, a lateralização das funções musicais pode ser diferente em músicos, comparado a indivíduos sem treinamento musical, o que sugere um papel da música na chamada plasticidade cerebral ${ }^{16,19,20}$.

\section{MÚSICA E LINGUAGEM}

Música é também linguagem. Segundo o eminente maestro e compositor Koellreutter, a música é uma arte que se utiliza de uma linguagem. É linguagem, uma vez que utiliza um sistema de signos estabelecidos naturalmente ou por convenção, que transmite informações ou mensagens de um sistema (orgânico, social, sociológico) a outro. Existem paralelos entre a linguagem verbal e a musical. Ambas dependem, do ponto de vista neurofuncional, das estruturas sensoriais responsáveis pela recepção e pelo processamento auditivo (fonemas, sons), visual (grafemas da leitura verbal e musical), da integridade funcional das regiões envolvidas com atenção e memória e das estruturas eferentes motoras responsáveis pelo encadeamento e pela organização temporal e motora necessárias para a fala e para a execução musical. No entanto, diferentemente da linguagem verbal, o código utilizado na música não separa significante e significado, uma vez que a mensagem da música não está condicionada a convenções semântico-lingüísticas, mas sim a uma organização que traduz idéias por uma estrutura significativa que é a própria mensagem: a própria música.

Do ponto de vista neuropsicológico, as estruturas envolvidas para o processamento musical são funcionalmente autônomas e diferentes daquelas envolvidas com a linguagem, isto é, fala, leitura e escrita ${ }^{18}$. Pesquisas em pacientes com lesão cerebral têm mostrado que a perda da função verbal (afasia) não é necessariamente acompanhada de perda das funções musicais (amusia). A existência de afasia sem amusia e a de amusia sem afasia indicam uma autonomia funcional dos processos neuropsicológicos inerentes aos sistemas de comunicação verbal e musical e uma independência estrutural de seus substratos neurobiológicos. A dissociação entre afasia e amusia é flagrante quando se analisam as manifestações neurológicas de grandes músicos vítimas de lesões cerebrais localizadas. Assim, o compositor russo V. I. Shebalin (1902-1963), após sofrer dois episódios de acidente vascular cerebral em território da cerebral média esquerda, apresentou afasia intensa, mantendo intacta sua habilidade para compor. O organista e compositor francês Jean Langlais (1907-1991) tornou-se afásico, aléxico e agráfico após hemorragia temporoparietal esquerda, mantendo, no entanto, inalterada sua capacidade para compor, improvisar e ler notação musical. Maurice Ravel (1875-1937), em virtude de uma provável doença degenerativa progressiva, apresentava dificuldade na transposição musical, isto é, na passagem da modalidade auditiva para a visual e/ou motora, estando preservadas a percepção e a idéia sonoras, que embora intactas em sua mente, estava incapacitado para expressá-las pela escrita e pela execução musical ${ }^{5}$.

\section{EPILEPSIA E MÚSICA}

Quando se analisam as relações entre a epilepsia e a música, dois aspectos devem ser ressaltados: a epilepsia musicogênica e o estudo das funções musicais em pacientes portadores de epilepsia parcial.

A epilepsia musicogênica corresponde à ocorrência de crises epilépticas desencadeadas por estímulos musicais ${ }^{11,21,22}$. Não constitui uma síndrome epiléptica, razão pela qual deve-se falar em "crises epilépticas desencadeadas por música". Trata-se de uma afecção rara (1 indivíduo em 10 milhões), ocorrendo geralmente após os 20 anos de idade. Muitos estudos indicam que esses pacientes são pessoas "interessadas em música".

Neurologicamente, as crises são geralmente parciais complexas, com freqüente generalização secundária e usualmente coexistindo com outros tipos de crises espontâneas. Etiologicamente são, muitas vezes, crises sintomáticas, relacionadas à epilepsia lesional. No trabalho original de Critchley ${ }^{11}$, descrevem-se 3 tipos de epilepsia denominada de acústico-motora. Um tipo seria a resposta à surpresa ou ao susto; o outro, perante estímulos musicais intoleráveis (para o indivíduo), evocadores ou que produzissem desagrado; e o terceiro tipo, mais raro, provocado por um estímulo de caráter monótono. $\mathrm{O}$ fato de diferentes tipos de crises coexistirem significa um indício fisiopatológico particularmente importante, por permitir a interpretação da epilepsia musicogênica como "o efeito da música em um cérebro epiléptico". As anormalidades elétricas (EEG) são geralmente temporais, em ambos hemisférios, e apenas poucos estudos assumem a localização temporal direita ou foco médio-temporal ${ }^{21,22}$. $\mathrm{O}$ autor refere-se à grande controvérsia relativa à fisiopatologia, de ser a crise o simples resultado de um ou vários estímulos que excitam o córtex cerebral, ou do recrutamento de áreas subcorticais e corticais amplas relacionadas com atenção, memória e associação musical ${ }^{11,21,22}$. 
Em relação à epilepsia parcial, podemos considerar que as pesquisas sobre estimulações elétricas realizadas em pacientes portadores de epilepsia do lobo temporal têm contribuído para o conhecimento de aspectos específicos das funções psicofísicas do cérebro, incluindo as funções musicais. Lesões e disfunções do lobo temporal podem incapacitar seriamente as habilidades musicais, como o canto ou a execução de sons, reconhecimento de sons e manutenção de ritmos $^{5,8,16,23}$.

Mediante estimulação elétrica do lobo temporal, principalmente do giro temporal superior, Penfield e Jasper ${ }^{12}$ surpreenderam-se com o número de vezes que o paciente relatava estar ouvindo música. Essa ocorrência verificava-se a partir de 17 pontos diferentes de estimulação elétrica, ocorrendo em uma freqüência de $3 \%$ dos casos com "epilepsia do lobo temporal". A multiplicidade de experiências relatadas pelos pacientes era grande, variando desde vozes, piano tocando ou uma orquestra executando peças musicais complexas.

Outras pesquisas envolvendo epilepsia e música também têm merecido especial atenção, como as que se referem às chamadas crises parciais psíquicas simples, durante as quais o paciente epiléptico pode relatar o que Penfield denominou resposta experiencial, a qual pode ser essencialmente auditiva e musical. O paciente pode recordar canções ouvidas na infância, ouvir vozes familiares, padrões sonoros complexos (ruídos) e até mesmo música orquestral ${ }^{24,25,26}$.

As crises epilépticas põem em evidência o mecanismo de funcionamento das áreas cerebrais, possibilitando o estabelecimento de uma relação entre determinadas alterações do comportamento e funções psíquicas com a localização e a lateralidade do foco ou da lesão.

França Correia et al. ${ }^{5}$ realizaram um estudo sobre a lateralização das funções musicais em pacientes com epilepsia parcial e sem conhecimento musical e concluíram que a presença do foco no hemisfério cerebral direito afeta o desempenho de funções de reconhecimento melódico, enquanto nos casos com foco no hemisfério esquerdo, a reprodução e a organização rítmicas são mais comprometidas.

\section{EFEITO MOZART}

$\mathrm{O}$ efeito Mozart, descrito por Rausher et al. ${ }^{27}$, bastante divulgado na mídia e alvo de inúmeras controvérsias na literatura, refere-se à descrição de melhora no desempenho neuropsicológico em provas espaciais, bem como mudanças neurofisiológicas, induzidas pela audição da música de Mozart. Mais recentemente, esse efeito foi investigado por Hughes et $a l .{ }^{28} \mathrm{em}$ relação à atividade paroxística eletrencefalográfica de pacientes epilépticos. Os autores observaram que a audição de Mozart (Sonata para dois pianos em Ré Maior, K448) produziu uma significativa redução da atividade paroxística interictal em 23 de 29 pacientes (79\%), incluindo pacientes em coma. Observaram, ainda, que não só a freqüência da atividade paroxística diminuía, mas também a amplitude das descargas. O mapeamento cerebral realizado durante a sonata mostrava diminuição da atividade teta e alfa nas regiões centrais, com aumento da atividade delta nas regiões central e média. Os autores sugeriram que a arquitetura complexa da música de Mozart poderia relacionar-se temporoespacialmente com a também complexa microorganização colunar do córtex cerebral (modelo trion), e semelhantemente à estimulação elétrica em padrão (como a observada após a estimulação da amígdala na freqüência de $1 \mathrm{~Hz}$ ) poderia levar ao aumento do limiar convulsivo e à diminuição das descargas paroxísticas no $E_{E G}{ }^{29}$. Embora interessante, tais achados requerem confirmação em novos trabalhos.

\section{CONSIDERAÇÕES FINAIS}

É importante que os trabalhos de música em neurociências surjam da interação multidisciplinar de músicos, musicoterapeutas, neurologistas, neurofisiologistas, possibilitando a ampliação de nossos horizontes em uma prática que integra profissionais que antes tinham suas atividades seccionadas. Isso pode permitir uma comunicação mais eficiente, inclusive em nível musical e estético propriamente dito, com doentes em busca de contato, isolados da comunicação por suas disfunções cerebrais e mentais. A busca de melhores correlações da música com a função cerebral irá exigir um trabalho multidisciplinar que considere a própria estrutura musical na formulação metodológica dos trabalhos. Tal intento poderá levar inclusive à criação de músicas, específicas para determinadas situações de disfunção neurológica, baseadas nos registros e na variabilidade dos próprios sinais biológicos tempodependentes, como, por exemplo, a atividade elétrica cerebral. O esforço de trazer a música para as ciências de saúde poderá representar, por um lado, a transcendência de uma prática musical hedonista baseada apenas no ouvir-prazer e, por outro, a ampliação da visão da própria neurociência, para além do enfoque racionalista, que negligencia o subjetivo e o relativo expresso nas artes. 


\section{SUMMARY}

Music and Neurosciences.

This article discusses the relationships between music and neuroscience particularly the brain organization of musical functions. Functional imaging studies found that lateralization and topography of brain activation depend on multiple factors such as familiarity to musical stimuli, cognitive strategy evolving melodic, rhythmic and timbre perception and previous musical training. Changes in brain electrical activity is suggested by musicogenic epilepsy, through phenomenological descriptions of partial seizures with "musical" symptoms and anedoctical reports of changes of interictal activity induced by listening to Mozart music.

\section{KEYWORDS}

Music, brain function, functional brain asymmetry.

\section{Referências}

1. Engel Jr J, Henry TR, Rissinger MW. Positron emission tomography. In: Luders HO (ed.). Epilepsy Surgery, Raven Press, New York, 1992, pp. 231-41.

2. Iwaki T, Hayashi M, Hore T. Changes in alpha band eeg activity in the frontal area after stimulation with music of different affective content. Perceptual And Motor Skills, 84:515-26, 1997

3. Mazziota JC, Phelps ME, Carson RE, Kuhl DE. Tomographic mapping of human cerebral metabolism: auditory stimulation. Neurology, 32:921-37, 1982.

4. Zatorre RJ, Evans AC, Meyer E. Neural mechanisms underlying melodic perception and memory for pitch. $J$ Neurosci, 14:1908-19, 1994

5. Correia CMF, Muszkat M, De Vincenzo NS, Campos CJR. Lateralização das funções musicais na epilepsia parcial. Arq Neuropsiquiatr, 56(4):747-55, 1998.

6. Sarnthein J, Vonstein A, Rappelsberger P, Petsche H, Rauscher FH, Shaw GL. Persistent patterns of brain activity: an EEG coherence study of the positive effect of music on spatial-temporal reasoning. Neurol Res, 19(2):107-16, 1997.

7. Tomaino CM. Clinical applications of music. In: Neurologic Rehabilitation, Mmb Music Inc, 1998.

8. Masui K, Niwa SI, Anzai N, Kameyama T, Saitoh O, Rymar $K$. Verbal memory disturbances in left temporal lobe epileptics. Cortex, 20:361-8, 1984.

9. Petsche $\mathrm{H}$, Pockberger H, Rappelsberger P. Eeg topography and mental performance. In: Frank Duffy, MD (ed.). Topographic mapping of brain electrical activity. Butterworths, Boston, 1986, pp. 63-9.

10. Bettermann $H$, Amponsah D, Cysarz D, Van Leeuwen P. Musical rhythms in heart period dynamics: a cross-cultural and interdisciplinary approach to cardiac rhythms. Am J Physiol, 277(5 Pt2):H1762-70, 1999.

11. Critchley, M. Musicogenic epilepsy. Brain, 60:1328, 1937.

12. Penfield $W$, Jasper HL. Epilepsy and the functional anatomy of the human brain. Boston, Little Brown And Company, 1954, p. 896 .

13. Platel H, Price C, Baron JC, Wise R, Lambert J, Frackowiak RSJ, Lechevalier B, Eustache J. The structural components of music perception. A functional anatomical study. Brain, 120:229-43, 1997
14. Kimura D. Left-right differences in perception of melodies Q J Exper Psychol, 16:335-58, 1964.

15. Zatorre RJ, Evans AC, Meyer E, Gjedde A. Lateralization of phonetic and pitch processing. Science, 256:846-9, 1992.

16. Liegeois-Chauvel C, Peretz I, Babai M, Laguitton V, Chauvel P. Contribution of different cortical areas in the temporal lobes to music processing. Brain, 121(Pt10):1853-67, 1998.

17. Heilman, KM, Bowers D, Valenstein E, Watson RT. The right hemisphere neuropsychological functions. J Neurosurg, 64:693-704, 1986.

18. Sergent J. Music, the brain and ravel. Tins, 16(5):168-72 1993.

19. Lauter JL, Herscovitch P, Formby C, Raichle ME. Tonotopic organization in huma auditory cortex revealed by positron emission tomography. Hear Res, 20:199-205, 1985.

20. Muszkat, M, Correia, CMF, Noffs, MHS, Vincenzo, NS, Campos, CJR. Especialização funcional hemisférica na afasia motora. Arq Neuropsiquiatria 53(1):88-93, 1995.

21. Wieser HG, Hungerbuhler H, Siegel AM, Buck A. Musicogenic epilepsy: review of the litterature and case report with ictal single photon emission computed tomography. Epilepsia, 38:200-7, 1997.

22. Zifkin BG, Zatorre RJ. Musicogenic epilepsy. Adv Neurol, 75:273-81, 1998 .

23. Gupta AK, Jeavons PM, Hughes RC, Covanis A. Aura in temporal lobe epilepsy. Clinical and electrencephalographic correlation. J Neurol Neurosurg Psychiatry, 46:1079-83, 1983.

24. King DW, Ajmone-Marsan A. Clinical features and ictal patterns in epilepitic patientes with eeg temporal lobe foci. Ann Neurol, 2:138-47, 1977.

25. Muszkat M. Teste de estimulação dicótica-consoante-vogal em pacientes com epilepsia parcial. Tese de mestrado. Departamento de Neurologia e Neurocirurgia. Escola Paulista de Medicina. São Paulo, 1989.

26. Muszkat, M. Estudo da especialização funcional hemisférica em paciente com epilepsia parcial através de teste taquistoscópico de dígitos. Tese de doutorado. Departamento de Neurologia e Neurocirurgia. Escola Paulista de Medicina. São Paulo, 1992.

27. Rauscher FH, Shaw K, KY, KN. Music and spatial task performance. Nature, 365: 611, 1993.

28. Hughes JR, Daaboul Y, Fino JJ, Shaw GL. The "Mozart effect" on epileptiform activity. Clinical Eletrooencephalography, 29(3):109-19, 1998

29. Weiss SRB, Li XL, Rosen JB, Li T, Heynen T, Post RM. Quenching: inhibition of development and expression of amygdala kindled seizures with low frequency stimulation. Neuroreport, 6:2171-6, 1995.

\section{Endereço para correspondência:}

Mauro Muszkat

Rua Borges Lagoa, 564 - conj 121 - Vila Clementino

CEP 04038-031 - São Paulo, SP

E-mail: mauromuszkat@yahoo.com.br 